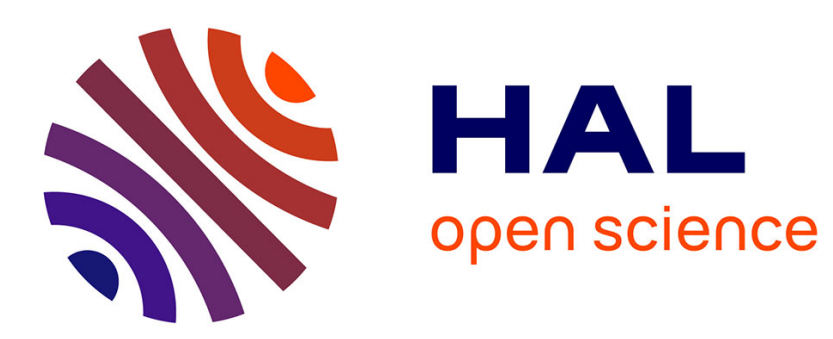

\title{
A Fracture Model Applied to the Ductile/Brittle Regime
} L. Xia, C. Fong Shih

\section{To cite this version:}

L. Xia, C. Fong Shih. A Fracture Model Applied to the Ductile/Brittle Regime. Journal de Physique IV Proceedings, 1996, 06 (C6), pp.C6-363-C6-372. 10.1051/jp4:1996636 . jpa-00254464

\section{HAL Id: jpa-00254464 https://hal.science/jpa-00254464}

Submitted on 1 Jan 1996

HAL is a multi-disciplinary open access archive for the deposit and dissemination of scientific research documents, whether they are published or not. The documents may come from teaching and research institutions in France or abroad, or from public or private research centers.
L'archive ouverte pluridisciplinaire HAL, est destinée au dépôt et à la diffusion de documents scientifiques de niveau recherche, publiés ou non, émanant des établissements d'enseignement et de recherche français ou étrangers, des laboratoires publics ou privés. 


\title{
A Fracture Model Applied to the Ductile/Brittle Regime
}

\author{
L. Xia and C. Fong Shih \\ Division of Engineering, Brown University, Providence, RI 02912, U.S.A.
}

\begin{abstract}
The fracture resistance of ferritic steels in the ductile/brittle transition regime is controlled by the competition between ductile tearing and cleavage fracture. Under typical conditions, a crack initiates and grows by ductile tearing but ultimate failure occurs by catastrophic cleavage fracture. In this paper the tearing process is simulated using void-containing cell elements embedded within a conventional elasticplastic continuum. Weakest link statistics is incorporated into the cell element model and this new model is employed to predict the onset of unstable cleavage fracture. Load-displacement behavior, ductile tearing resistance and transition to cleavage fracture are investigated for three different test geometries. The model predicts trends in ductile/brittle transition that are consistent with experimental data.
\end{abstract}

\section{INTRODUCTION}

Cleavage fracture and ductile tearing are competing mechanisms in the ductile/brittle transition regime of ferritic steels. In this regime, a ferritic steel structure can withstand significant amounts of ductile tearing without substantial loss of its load bearing capacity. However, many experiments show that stable crack growth by ductile tearing eventually gives way to catastrophic cleavage fracture. The latter appears to be the critical failure mechanism limiting the load bearing capacity of the structure. Hence there is great interest in a predictive model for cleavage fracture.

Experimental data on cleavage fracture tend to be highly scattered. Two reasons have been offered for the large variations in measured cleavage fracture toughness at a given temperature within the transition region. First, cleavage fracture toughness in the transition region is controlled in large part by statistical sampling of a critical cleavage crack nucleus. Second, the level of stress triaxiality ahead of the crack tip is a strong function of the geometry of the crack and the amount of crack growth. Therefore the population of eligible particles for cleavage fracture depends implicitly on crack geometry and this population changes as the crack grows because of alterations in stress triaxiality.

The important role of carbides in cleavage fracture is well established by numerous studies. Transgranular cleavage fracture in ferritic steels is attributed to slip-induced cracking of carbide particles located on grain boundaries and the dynamic propagation of such cracks into the surrounding ferrite matrix. Ritchie, Knott and Rice [1] proposed that this event can be related to the attainment of a critical stress intensification at the crack tip such that the local tensile stress exceeds the critical fracture stress over a characteristic distance ahead of the crack tip. The characteristic length in question has been interpreted by weakest link statistical strength considerations related to carbide size and spacing distribution and by taking into account that carbides are embedded in stress fields exhibiting high stress gradients, e.g. Curry and Knott [2], Pineau [3], Beremin [4], Evans [5], Wallin, Saario, and Törrönen [6] and Lin, Evans and Ritchie [7] and Mudry [8]. These investigators made attempts to predict the effects of carbide size and spacing distribution and grain size on cleavage fracture toughness $K_{C}$ among other things. More recently, constraint effects 
on cleavage fracture toughness were considered by Anderson and Dodds [9], Wang [10], Wallin [11] and Koers, Krom and Bakker [12]. The studies noted above have provided insights into the role of microstructure and constraint on cleavage fracture toughness and some models predict trends in toughness that are in qualitative agreement with available test data.

A model for cleavage fracture based on weakest link statistics is presented in this work. Our approach differs from previous analyses in several important ways. We are fully cognizant of the fact that cleavage fracture in the ductile/brittle transition is usually preceded by ductile tearing and that the amount of tearing strongly depends on microstructure and constraint because ductile tearing is the precursor to cleavage fracture and both mechanisms are competing failure modes, the success of the predictive approach to be outlined relies upon accurate modeling of the process of ductile crack growth. In this work, ductile tearing in a progressively cavitating solid is modeled by void-containing cell elements embedded within a conventional elastic-plastic continuum. The linear dimension of voided cell elements is related to the mean spacing between large inclusions. These cell elements incorporate the softening characteristics of hole growth and it strong dependence on stress triaxiality. Under increasing strain, the voids grow and coalesce to form new crack surfaces thereby advancing the crack. This computational model is applied to three test geometries which are known to give rise to significantly different crack tip constraints. The fields that evolve ahead of the advancing crack are used in conjunction with a statistical model based on the weakest link concept to compute the Weibull stress and the cumulative probability of cleavage fracture. Several aspects of the present model were discussed in our previous work (see Shih and Xia [13], Xia, Shih $[14,15,16]$ and Xia, Shih and Hutchinson [17]).

The primary microstructural parameters in our model are $D$ and $f_{0}$ characterizing the spacing and the initial volume fraction of large voids (sulphide and oxide inclusions) and $m_{s}$ characterizing the size distribution of carbide particles. Once these material parameters have been specified, this approach permits computation of relationships among loads, displacements, crack growth, Weibull stress, and the probability of cleavage fracture for the crack geometry of interest. The computational model places no restrictions on the amount of ductile tearing and plastic deformation. To the extent that the parameters $D, f_{0}$ and $m_{s}$ are representative of the actual microstructure, this model could be used to gain a better understanding of how microstructure and crack geometry can affect the competition between ductile tearing and cleavage fracture.

\section{MODEL FOR DUCTILE TEARING}

As already noted the ductile tearing process is simulated using void-containing cell elements, whose linear dimension, $D$, is related to the mean spacing between large inclusions. Each cell element contains a centered spherical void of initial volume fraction $f_{0}$. The growth of this void and the associated softening of the cell is described by Gurson constitutive relation (Gurson [18]). These cells elements are embedded within the conventional elastic-plastic continuum referred to as the background material. At the heart of Gurson's relation is the yield condition

$$
\Phi=\left(\frac{\sigma_{e}}{\bar{\sigma}}\right)^{2}+2 q_{1} f \cosh \left(\frac{3 q_{2} \sigma_{m}}{2 \bar{\sigma}}\right)-\left[1+\left(q_{1} f\right)^{2}\right]=0 .
$$

Here $\sigma_{e}$ is the macroscopic effective Mises stress formed using the Cauchy stress, $\sigma_{m}$ is the macroscopic mean stress, $\bar{\sigma}$ is current flow stress of the matrix, $f$ is the current void volume fraction, and $q_{1}$ and $q_{2}$ are the adjustment factors introduced by Tvergaard [19] to improve the accuracy of the model. $q_{1}=1.25$ and $q_{2}=1.0$ were employed in the calculation reported below.

The rate of growth of the void volume fraction is given by

$$
\dot{f}=(1-f) \dot{\varepsilon}_{k k}^{p}
$$

The Gurson model does not capture the final phase of the coalescence process and it is necessary to incorporate a criterion for the final material separation. To model the rapid loss of stress carrying capacity in this final stage of material separation, a linear cell traction (reduction) vs. elongation 


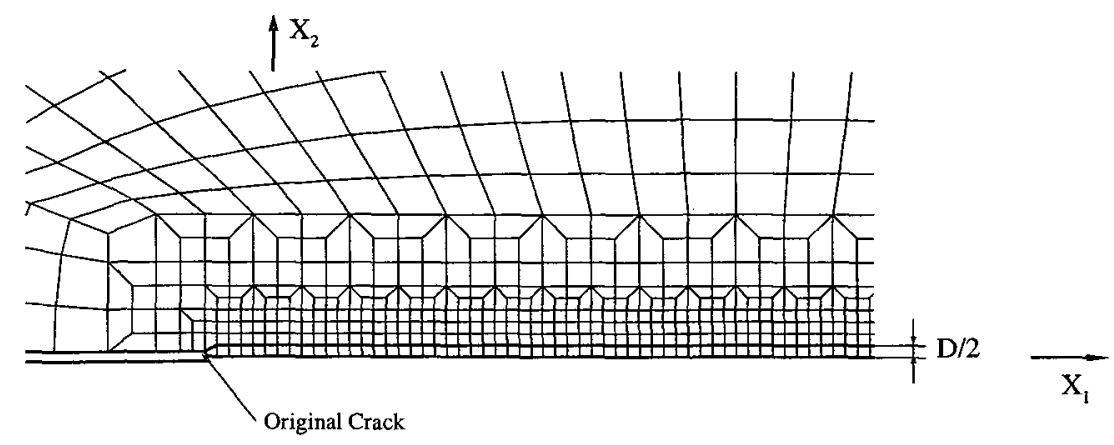

Fig. 1 Layer of void-containing cell elements along crack plane and surrounding elements.

relation is activated when the void volume fraction in a given cell reaches $f_{E} ; f_{E}=0.2$ was used in present calculation. A discussion of the coalescence process and the resulting traction-elongation behavior can be found in Faleskog and Shih [20].

In this study, the uniaxial stress-strain behavior of both the void-free background material and the matrix material within the void-containing layer are described by the following true stresslogarithmic strain relation

$$
\begin{array}{ll}
\varepsilon=\frac{\sigma}{E} & \sigma<\sigma_{0} \\
\varepsilon=\frac{\sigma_{0}}{E}\left(\frac{\sigma}{\sigma_{0}}\right)^{1 / N} & \sigma \geq \sigma_{0},
\end{array}
$$

where $E$ is Young's Modulus, $N$ is the strain hardening exponent and $\sigma_{0}$ is the initial tensile yield stress.

The following material properties

$$
E / \sigma_{0}=500, \quad N=0.1, \quad \nu=0.3, \quad \sigma_{0}=400 \mathrm{MPa}
$$

are used in all computations reported in this paper. These values are representative of a moderate hardening material, e.g. A533B steels.

The finite element analysis is carried out for the mode I, plane strain crack growth in three different test specimen: three-point-bend (TPB) specimen, double edge notched tension (DENT) panel and center cracked panel (CCP). The ratio of initial crack length to specimen width, $a / W$, is taken as 0.6 for all three specimens. Due to the symmetry, only one-half of the geometry is modeled for TPB and quarter of geometry for DENT and CCP. We employ quadrilateral elements each of which is comprised of four cross-triangular elements. Figure 1 shows a row of uniformly sized void-containing elements with dimension $D / 2 \times D / 2$ is arranged directly ahead of initial crack tip.

\section{WEAKEST LINK MODEL FOR CLEAVAGE FRACTURE}

Treatment of the initiation of unstable cleavage fracture by way of extreme value statistics has been discussed by Beremin [4], Mudry [8], Wang [10], Wallin [11], and Koers, Krom and Bakker [12] among others. In these studies a weakest link mechanism is assumed for cleavage fracture. That is to say, at some point during the loading, a microcrack nucleates at a critical second phase inclusion and this event is sufficient to precipitate catastrophic cleavage fracture. In what follows, 
we will only state the model for the abrupt termination of ductile tearing by catastrophic cleavage fracture in the ductile/brittle transition. The detailed arguments can be found in Xia and Shih $[16]$.

The three-parameter Weibull model can be expressed as

$$
P_{f}=1-\exp \left[-\left(\frac{\sigma_{W}}{\sigma_{u}}\right)^{m_{s}}\right]
$$

with $\sigma_{W}$ as the Weibull stress:

$$
\sigma_{W}=\left[\sum_{i=1}^{n}\left(\sigma_{1}^{i}-\sigma_{\mathrm{th}}\right)^{m_{s}} \frac{V_{i}}{V_{0}}\right]^{1 / m_{s}} \text { for } V_{\mathrm{i}} \text { where } \sigma_{1}^{\mathrm{i}} \geq \sigma_{\mathrm{th}} \text { and } \vec{\varepsilon}>0 .
$$

where $m_{s}$ is a shape factor, $\sigma_{\text {th }}$ a threshold stress and $\sigma_{u}$ a scaling stress. If $\sigma_{\text {th }}$ is taken to be zero, (5) reduces to the two-parameter Weibull form. The stress $\sigma_{1}^{i}$ is the average maximum principal stress for the $i^{\text {th }}$ volume element the average being taken over the four sub-elements comprising the $i^{\text {th }}$ element. This averaging technique is consistent with our cell element concept based on the notion of a quasi-homogeneous stress state. $V_{i}$ is the volume of the $i^{\text {th }}$ element, which is scaled by $V_{0}$, a reference unit volume. Note that the volume $V_{i}$ should be taken as $A$ rea $\times \mathrm{B}$ (the specimen thickness) for the plane strain analysis undertaken here.

There is broad agreement that $m_{s}, \sigma_{\mathrm{th}}$ and $\sigma_{u}$ are material parameters which can be calibrated from experiment data. The Weibull modulus, $m_{s}$, is a temperature-independent material constant which measures the scatter of experimental data attributed to the size distribution of cleavage fracture triggering inclusions. The threshold stress, $\sigma_{\mathrm{th}}$, represents a lower bound strength (associated with the largest feasible cracked particle) and its use avoid the otherwise unrealistic result that a vanishingly small stress will still yield a non-zero probability of cleavage fracture. Once these parameters have been specified (or calibrated) for the material of interest, the statistical approach permits computation of relationships among loads, displacements, extent of stable crack growth, $\sigma_{W}$ and $P_{f}$ with no restrictions on the extent of plastic deformation and the amount of stable ductile crack advance. In the absence of extensive experimental data, we took $m_{s}=1.5$ and $\sigma_{\text {th }}=2.5 \sigma_{0}$. These choices are somewhat arbitrary but are consistent with the values reported in the literature (e.g. Lin et al. [7]; Wang [10]; Koers et al. [12]).

The Weibull stress, $\sigma_{W}$, incorporates the magnifying effect of volume measured by the number of unit volumes - this number is inversely proportional to the magnitude of $V_{0}$. Therefore, $\sigma_{W}$ depends on the choice of $V_{0}$. The reference volume $V_{0}$ is arbitrary; however it should not be changed for the material under study. That is, the Weibull stress for different test specimens must be computed using the same $V_{0}$.

The scaling stress $\sigma_{u}$ also depends on the choice of $V_{0}$. As already noted, $\sigma_{u}$ and $V_{0}$ can be combined into a single scaling parameter, $\sigma_{u}^{m_{s}} V_{0}$, and it is this combination which should be regarded as a material constant. Indeed the partitioning of the latter into $\sigma_{u}$ and $V_{0}$ is a matter of convenience. It is important to note that a particular choice of $V_{0}$ does not affect the ranking of crack geometries by cleavage probability (as long as the same $V_{0}$ is employed in every case).

It is a common practice that the Weibull stress $\sigma_{W}$ at the cumulative probability of failure, $P_{\text {rank }}=63.2 \%$ (or $1-1 / e$ ), is the value assigned as $\sigma_{u}$ Here, $P_{\text {rank }}$ denotes the rank probability of cleavage fracture taking account of all test specimens. Because the purpose of the present exploratory work is to show trends we chose $\sigma_{W}$ corresponding to $J \simeq 250 \mathrm{~kJ} / \mathrm{m}^{2}$, for ductile crack growth in the deeply cracked three-point-bend geometry, as the value for $\sigma_{u}$, i.e. $\sigma_{u}=1976 \sigma_{0}$. As already noted, this choice does not affect the conclusions with regard to the effects of geometry. and ductile tearing on cleavage fracture.

\section{RESULTS AND DISCUSSIONS}

Under typical conditions, a crack in a metal initiates by ductile tearing. Holes nucleate from (weak) large inclusions at relatively low stress and grow to large sizes under increasing stress. rapidly 

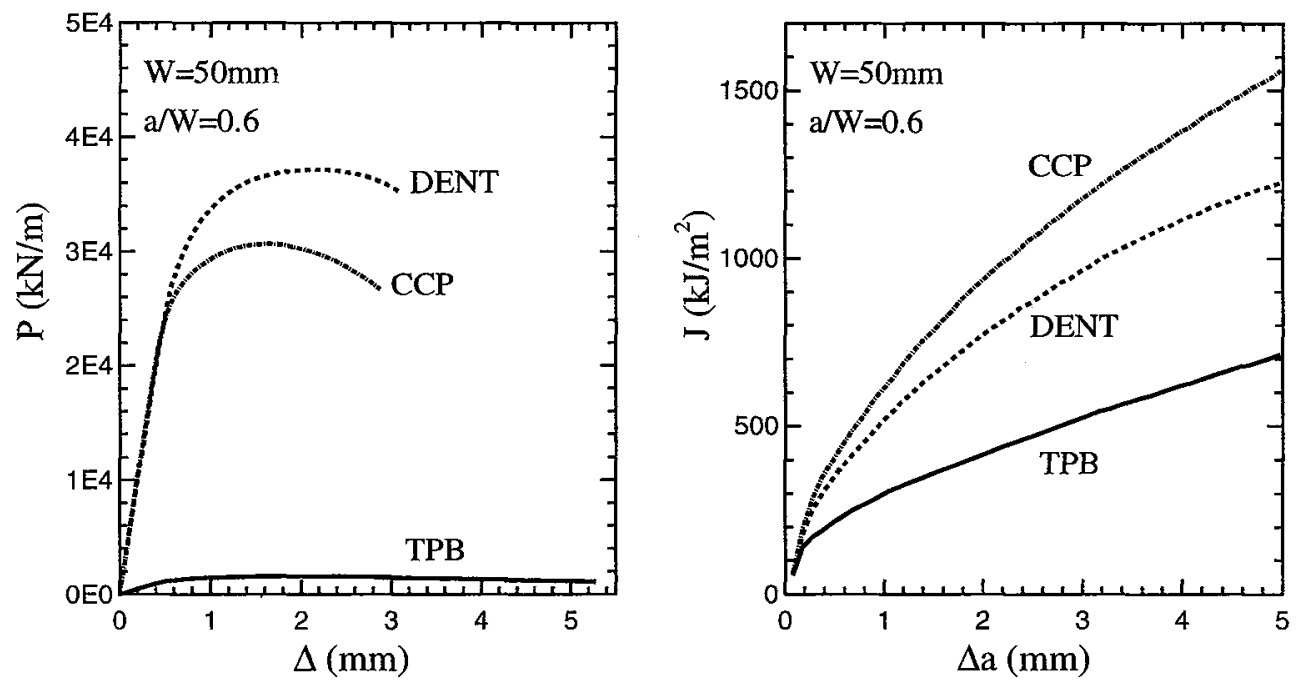

Fig. 2 Ductile crack growth for three different geometries, TPB, DENT and CCP. W $=50 \mathrm{~mm}, \mathrm{a} / \mathrm{W}=0.6 ; \mathrm{E} / \sigma_{0}=500$, $\mathrm{N}=0.1, \nu=0.3, \mathrm{D}=200 \mu \mathrm{m}$ and $f_{0}=0.005$. (a) Load-displacement curves. (b) J-resistance curves.

growing holes join together, thus advancing the crack. In the ductile/brittle transition region, the highly dissipative process of ductile tearing eventually gives way to catastrophic cleavage fracture attributed to the unstable cracking of carbide particles generally located on grain boundaries. Recent computational studies have shown that ductile crack growth can elevate crack tip constraint thereby increasing the propensity for cleavage fracture. It is quite evident that the final outcome of this continuing competition between - (i) the ductile tearing and (ii) unstable microcrack nucleation from carbides which can result in cleavage fracture - is determined by microstructure and carbide size distribution as well as by external factors such as crack tip constraint and specimen size.

\subsection{Preceding ductile crack growth}

Figure 2 shows computed load-displacement relations and fracture resistance curves for ductile crack growth in three different specimens, TPB, DENT and CCP. The geometry dependence of crack growth resistance can be seen clearly. The results in Fig. 2 and subsequent results are computed using $D=200 \mu \mathrm{m}$ and $f_{0}=0.005$. They are the same parameters employed in studies by Xia, Shih and Hutchinson [17] which successfully predicted the ductile fracture behavior of A533B steels.

Figure 3 displays the tensile stress distributions ahead of the crack tip for growth $\Delta a=D, 10 D$ and $20 D$ for the specimens considered in Fig. 2. We can see that, the tensile stresses gradually increase along with the crack growth. Especially in DENT and CCP this gradual stress elevation with the crack growth become much more evident. The steady elevation of crack tip constraint with ductile crack growth can increase the risk of cleavage fracture which will be taken up later.

Contour maps of the maximum principal stress provide the most compelling description of constraint evolution. Figure 4 displays stress contours for the three different crack geometries in question. First, study Fig. 4(a), (b) and (c) which shows the stress contours for three different amounts of crack growth in TPB. Focus on the innermost deep dark zone corresponding to $\sigma_{1} / \sigma_{0} \geq$ 


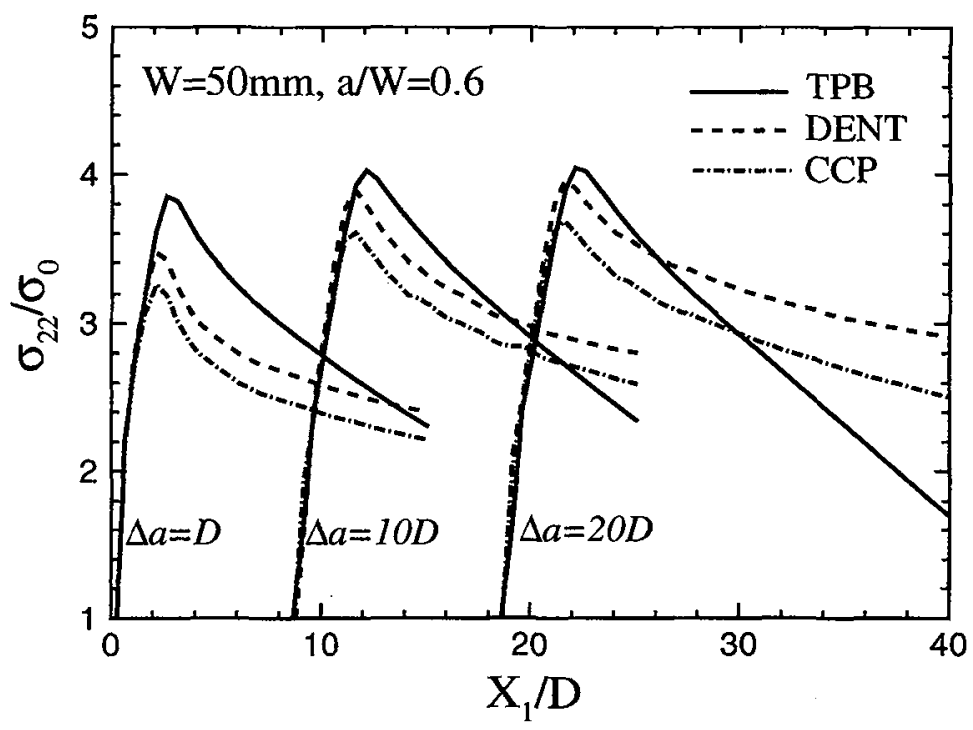

Fig. 3 Ductile crack growth for three different geometries, TPB, DENT and CCP. Distribution of tensile stress for $\Delta \mathrm{a}=\mathrm{D}, 10 \mathrm{D}$ and $20 \mathrm{D}$. $\mathrm{W}=50 \mathrm{~mm}, \mathrm{a} / \mathrm{W}=0.6 ; \mathrm{E} / \sigma_{0}=500, \mathrm{~N}=0.1, \nu=0.3, \mathrm{D}=200 \mu \mathrm{m}$ and $f_{0}=0.005$.

3.5 and follow the progression of its size beginning from $\Delta a=D$. The size of the high stress zone grows and quickly reaches a maximum; Now contrast this with the contour maps displayed in Fig. 4(d), (e) and (f) for DENT. The initial size of the high stress zone, $\sigma_{1} / \sigma_{0} \geq 3.5$, is barely perceptible on the scale of the plot. However, this zone expands at a phenomenal rate so that at $\Delta a=20 D$ the linear extent of the high stress zone has increased dramatically! Fig. 4(g-i) also display the stress contours for CCP. The zone of high stress also expands considerably but is smaller than the zones found in the two other geometries.

\subsection{Catastrophic cleavage fracture}

The Weibull stress incorporates the combined effect of sampling volume and load intensity. It can be seen from (6) that the relation between $\sigma_{W}$ and cumulative probability of fracture $P_{f}$ depends on a material scaling parameter $\sigma_{u}$ and a microstructural parameter $m_{s}$. For a given material $P_{f}$ depends on $\sigma_{W}$ alone. It necessarily follows that the crack geometry, the applied load and the (ductile) crack growth history can enter into cleavage predictions through $\sigma_{W}$ only.

The Weibull stress $\sigma_{W}$ provides a means to determine among other things the evolution of $P_{f}$ with load carried by the structure, or the $J$-integral, and to compare these quantities for different geometries at similar risk of fracture. As an application we compute the Weibull stress for the three crack geometries under study. This stress is obtained using (6) and the finite element solutions for the growing crack, which were discussed in connection with Figs. 2 through 4 . In this exploratory parametric study, Weibull parameters, $m_{s}=1.5$ and $\sigma_{\text {th }} / \sigma_{0}=2.5$. $V_{0}$ is chosen as $100 \mu \mathrm{m} \times 100 \mu \mathrm{m} \times 100 \mu \mathrm{m}$ and this unit volume is applied to calculations involving all three geometries. The specimen width $B$ is taken to be $B=W / 2$.

Figure 5 displays Weibull stress vs. $J$-integral for three different specimens. The solid lines are Weibull stresses computed using current values of $\sigma_{1}^{i}$. The trends are clear. Initially, the Weibull stress of TPB increases quickly but reaches a relatively lower level. In comparison, the 

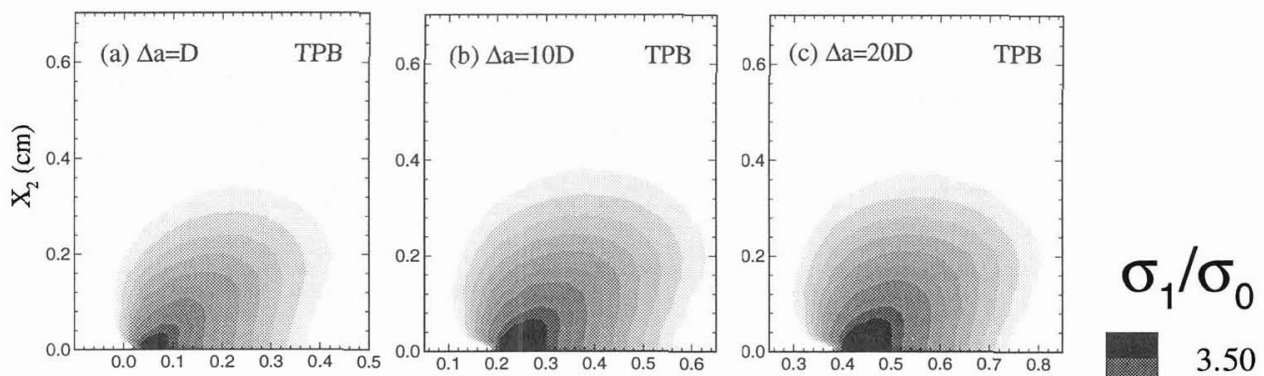

3.50

3.33
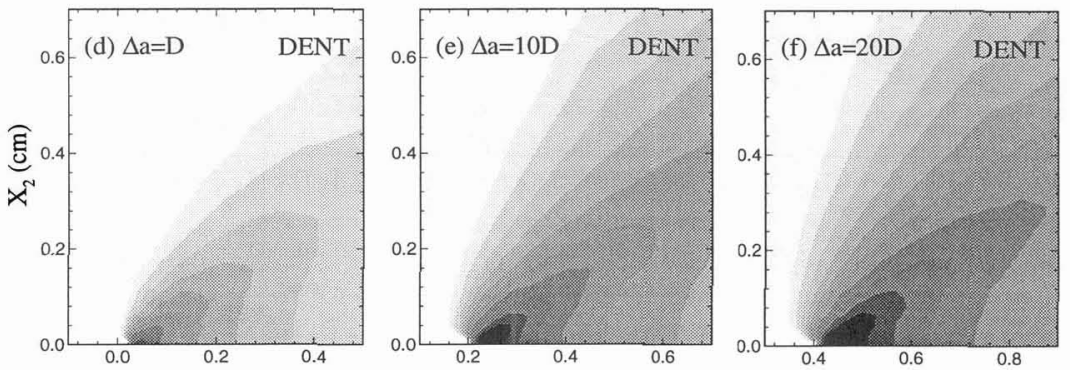

3.17

3.00

2.83

2.67

2.50

2.33

2.17

2.00
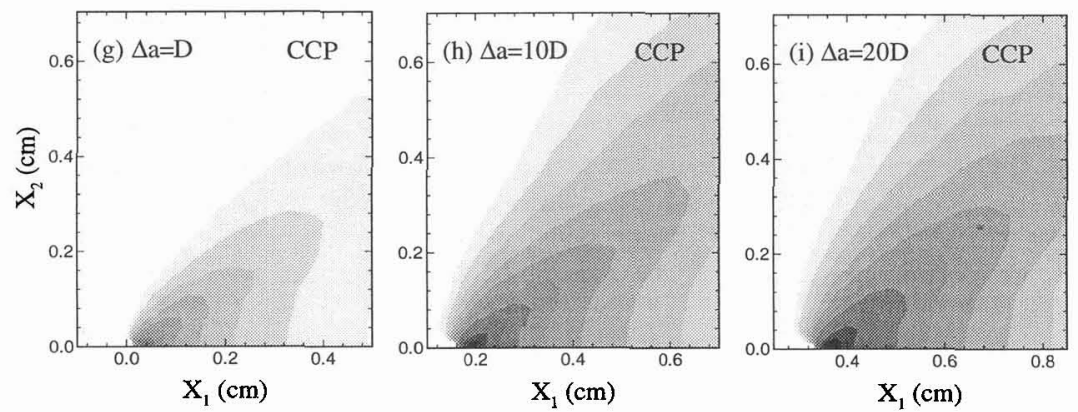

Fig. 4 Contour maps of maximum principal stress for crack advance equal to $\Delta a=D, 10 \mathrm{D}$ and $20 \mathrm{D}$ in three different geometries, TPB, DENT and CCP. $\mathrm{W}=50 \mathrm{~mm}, \mathrm{a} / \mathrm{W}=0.6 ; \mathrm{E} / \sigma_{0}=500, \mathrm{~N}=0.1, \nu=0.3, \mathrm{D}=200 \mu \mathrm{m}$ and $f_{0}=0.005$. 


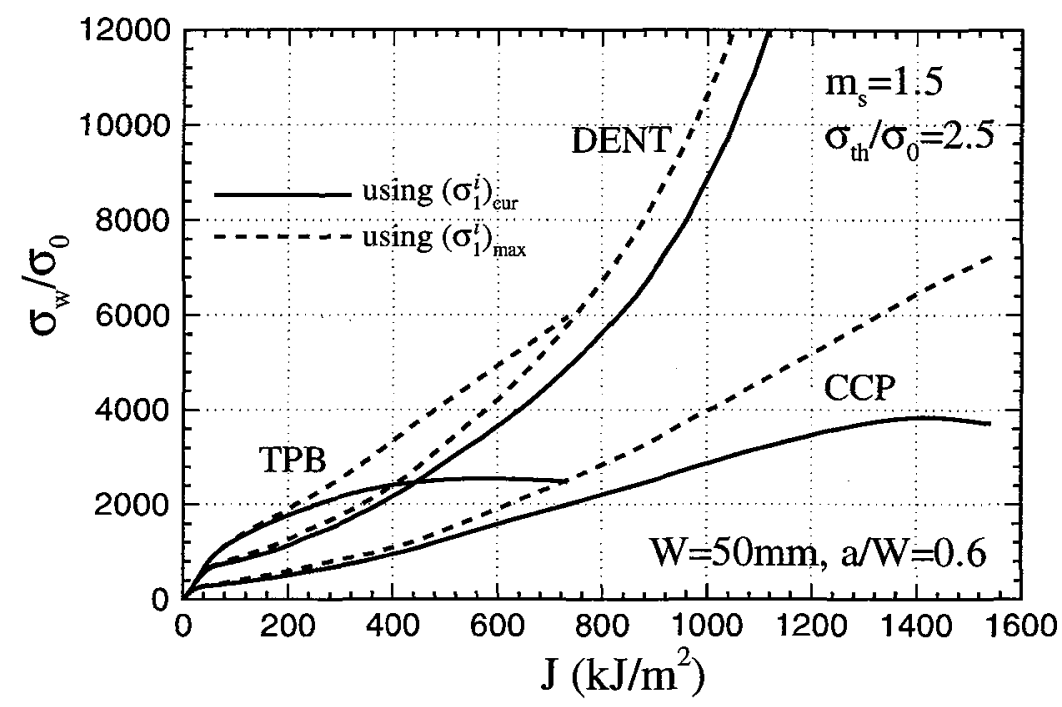

Fig. 5 Variation of Weibull stress with J-integral for three different specimens TPB, DENT and CCP.

curve of DENT can eventually reach a higher level. Weibull stress curve of CCP, on the other hand, is always lower. The dashed lines show Weibull stresses computed using the maximum value attained by $\sigma_{1}^{i}$ over the stress history of cell $\mathrm{i}$, up to the present point of interest. Here, the Weibull stress increases monotonically with $\mathrm{J}$. It can be seen that two schemes for computing the Weibull stress do not yield significantly different results when the constraint increases steadily with crack growth as in the DENT specimen. However, the trends are quite different in the case of the TPB specimen where the constraint decreases for extended amounts of crack growth.

Figure 6 displays the probabilities of cleavage fracture as a function of $J$-integral and as a function of crack growth, which are based on $\sigma_{\mathrm{w}}$ computed from current values of $\sigma_{1}^{i}$. Consider cleavage fracture probability at $50 \%$, which is of obvious engineering interest. We find from Fig. 6(a) that $J_{C}=192 \mathrm{~kJ} / \mathrm{m}^{2}$ for TPB, $J_{C}=290 \mathrm{~kJ} / \mathrm{m}^{2}$ for DENT and $J_{C}=590 \mathrm{~kJ} / \mathrm{m}^{2}$ for CCP. That is, the cleavage toughness for the geometry with the lowest constraint is more than three times larger! Using Fig. 6(b), we can also determine the amount of ductile crack growth preceding cleavage fracture. They are $\Delta a=0.29,0.35$ and $0.93 \mathrm{~mm}$ for TPB, DENT and CCP in that order. The predicted trend in toughness with crack geometry has been observed in a number of experimental studies, e.g. Betegón and Hancock [21], Sumpter [22], and Kirk et al. [23].

\section{CONCLUDING REMARKS}

An important first step in applying the present model involves the selection or calibration of several primary damage parameters. The ductile tearing parameters $D$ and $f_{0}$ have a microstructural basis, characterizing the spacing between large voids (or particles) and the initial volume fraction which could be identified by metallurgical studies of fracture specimen surfaces. In applications to date, $D$ and $f_{0}$ are used in a phenomenological manner in that they are chosen to reproduce cracked specimen data for the material of interest.

In applying the model to the transition region where cleavage is a competing failure mechanism, it is preferable to calibrate the parameters in the ductile/cleavage model in two phases. First, calibrate $D$ and $f_{0}$ following the steps described above. The fitting should be carried out using 

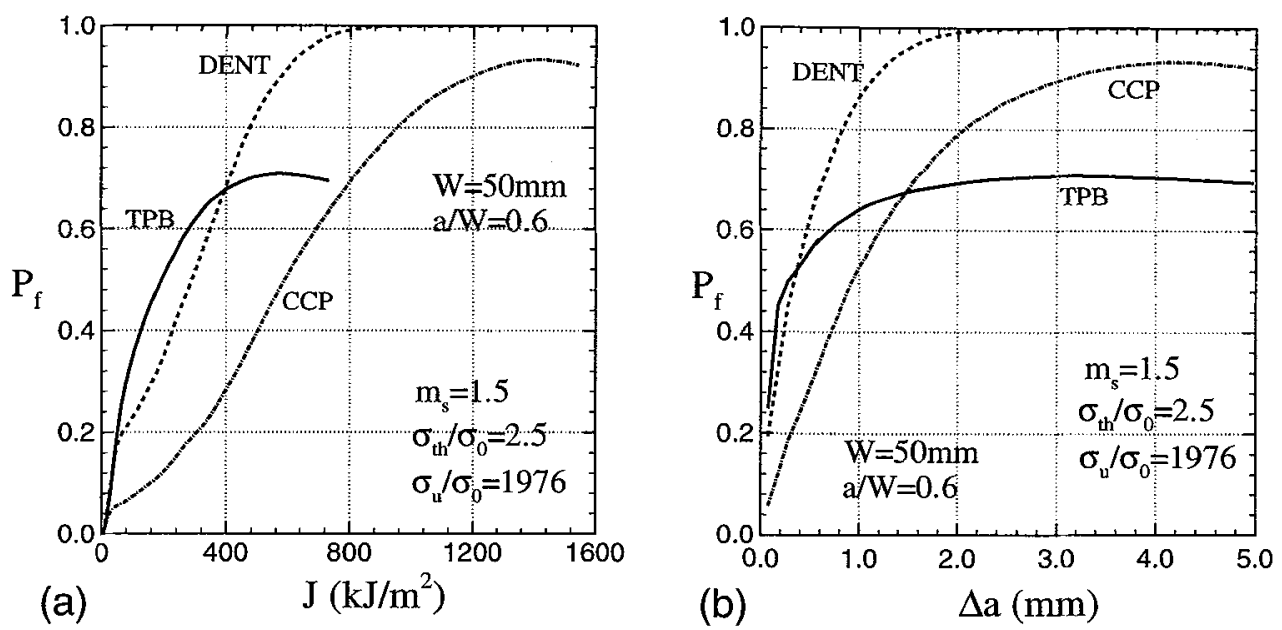

Fig. 6 Probabilities of cleavage fracture, $P_{f}$, for three different specimens TPB, DENT and CCP. W=50mm, a/W=0.6. (a) $P_{f}$ vs. $J$-integral. (b) $P_{f}$ vs. crack advance.

a set of test data containing significant amounts of (ductile) crack growth. This assures that the model reproduces correctly the experimental data of ductile crack growth. The statistical parameters are calibrated in the second phase. Here, data from many different test geometries is needed for fitting the primary statistical parameter $m_{s}$. For each set of test data, a crack growth analysis is performed for that test specimen using the calibrated ductile model. Based on a first guess of $m_{s}$ and $\sigma_{\mathrm{th}}$, one extracts the Weibull stress, $\sigma_{W}$, at cleavage fracture for the test specimen under study from the finite element solution of the growing crack by post-processing. The above analysis is repeated for all specimens tested in order to determine the Weibull stress at cleavage fracture for the different specimens. These results can now be used to construct a Weibull diagram of $P_{j}$ vs. $\sigma_{W}$. From this diagram one can judge the quality of the fit, and now iterate on $m_{s}$. The calibrated statistical model should reproduce the experimentally measured variations in cleavage fracture toughness.

The present model shows considerable promise as a predictive tool for nonlinear fracture mechanics analysis in the transition and upper shelf region. The model predicts correctly the effects of microstructure, constraint and loading rate on the overall load-displacement behavior, the ductile tearing resistance, and the termination of tearing by unstable cleavage fracture in the ductile/brittle transition regime. Specifically, model predictions of crack geometry and crack growth effects on cleavage fracture toughness reveal trends that are in agreement with available measurements.

\section{Acknowledgements}

This investigation is supported by Grant N00167-K-0038 from David Taylor Research and Development Center funded by the Nuclear Regulatory Commission and by Grant N00014-95-1-0399 funded by the Office of Naval Research. 


\section{References}

[1] Ritchie R.O., Knott J.K. and Rice J.R., J. Mech. Phys. Solids 21 (1973) pp.395-410.

[2] Curry D.A. and Knott J.F., Met. Sci. 13 (1979) pp.341-345.

[3] Pineau A., Advances in Fracture Research: ICF5 Conf., D. Francois et al. Eds. (1981) pp.533-577.

[4] Beremin F.M., Metall. Trans. A 14A (1983) pp. 2277-2287.

[5] Evans A.G., Metall. trans. A 14A (1983), pp. 1349-1355.

[6] Wallin K., Saario T. and Törrönen K., Met. Sci. 18 (1984) pp. 13-16.

[7] Lin T., Evans A.G. and Ritchie R.O., J. Mech. Phys. Solids 34 (1986) pp. 477-497.

[8] Mudry F., Nucl. Eng. Des. 105 (1987) pp. 65-76.

[9] Anderson T.L. and Dodds, R.H. Jr., J. Test. Eval.. 19 (1991) pp. 123-134.

[10] Wang Y.Y., Ph. D. Thesis (1991) Department of Mechanical Engineering, MIT.

[11] Wallin K., in Constraint Effects in Fracture, ASTM STP 1171, E.M. Hackett, K.-H. Schwalbe and R.H. Dodds Eds. (1993) pp. 264-288.

[12] Koers R.W.J., Krom A.H.M. and Bakker A., in Constraint Effects in Fracture, Theory and Applications, ASTM STP 1244, M. Kirk and A. Bakker Eds. (1994) pp. 191-208.

[13] Shih C.F. and Xia L., in Constraint Effects in Fracture, Theory and Applications, ASTM STP 1244, M. Kirk and A. Bakker Eds. (1994) pp. 163-190.

[14] Xia L. and Shih C.F., J. Mech. Phys. Solids 43 (1995) pp. 233-259.

[15] Xia L. and Shih C.F., J. Mech. Phys. Solids 43 (1995) pp. 1953-1981.

[16] Xia L. and Shih C.F., J. Mech. Phys. Solids 44 (1996) pp. 603-639.

[17] Xia L., Shih C.F. and Hutchinson J.W., J. Mech. Phys. Solids 43 (1995) pp. 389-413.

[18] Gurson A.L., J. Eng. Mat. Tech. 99 (1977) pp. 2-15.

[19] Tvergaard V., Int. J. Fract. 17 (1981) pp. 389-407.

[20] Faleskog, J.P. and Shih, C.F. (1995) Micromechanics of Coalescence - I. Synergistic Effects of Elasticity, Plastic Yielding and Multi-Size-Scale Voids. J. Mech. Phys. Solids. To appear.

[21] Betegón C. and Hancock J.W., ECF 8 Fracture Behaviour and Design of Materials and Structures, Volume II, D. Firraro Eds. Engineering Materials Advisory Services, Ltd., Warly, U.K. (1990),pp. 999-1002.

[22] Sumpter J.D.G., in Constraint Effects in Fracture, ASTM STP 1171, E.M. Hackett, K.-H. Schwalbe and R.H. Dodds Eds. (1993), pp. 492-502.

[23] Kirk M.T., Koppenhoefer K.C. and Shih C.F., inConstraint Effects in Fracture, ASTM STP 1171, E.M. Hackett, K.-H. Schwalbe and R.H. Dodds Eds. (1993) pp.79-103. 